WellBeing International

WBI Studies Repository

10-2006

\title{
Identifying and Preventing Pain in Animals
}

\author{
Daniel M. Weary \\ University of British Columbia \\ Lee Niel \\ University of British Columbia \\ Frances C. Flower \\ University of British Columbia \\ David Fraser \\ University of British Columbia
}

Follow this and additional works at: https://www.wellbeingintlstudiesrepository.org/assawel

Part of the Animal Studies Commons, Other Animal Sciences Commons, and the Other Anthropology Commons

\section{Recommended Citation}

Weary, D. M., Niel, L., Flower, F. C., \& Fraser, D. (2006). Identifying and preventing pain in animals. Applied animal behaviour science, $100(1), 64-76$.

This material is brought to you for free and open access by WellBeing International. It has been accepted for inclusion by an authorized administrator of the WBI Studies Repository. For more information, please contact wbisr-info@wellbeingintl.org.

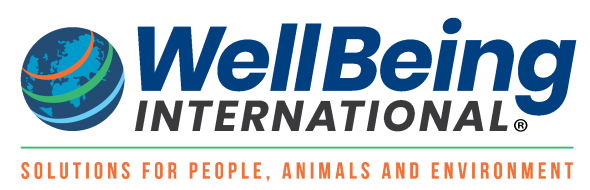




\title{
Identifying and Preventing Pain in Animals
}

\author{
Daniel M. Weary, Lee Niel, Frances C. Flower, David Fraser \\ University of British Columbia
}

\section{KEYWORDS}

pain assessment, pain prevention, animal welfare

\begin{abstract}
Animals are routinely subjected to painful procedures, such as tail docking for puppies, castration for piglets, dehorning for dairy calves, and surgery for laboratory rats. Disease and injury, such as tumours in mice and sole ulcers on the feet of dairy cows, may also cause pain. In this paper we describe some of the ways in which the pain that animals experience can be recognized and quantified. We also describe ways in which pain can be avoided or reduced, by reconsidering how procedures are performed and whether they are actually required. Ultimately, reducing the pain that animals experience will require scientific innovation paired with changed cultural values, and willingness to address regulatory, technological and economic constraints.
\end{abstract}

\section{Perspectives on animal pain}

Of all the affective states that animals experience, pain is of special interest. Intentionally causing pain to another human is considered among the most socially abhorrent of actions. Likewise, painful procedures performed on animals are among the most emotive of public concerns about animal welfare. The way our methods of caring for animals results in their pain or discomfort, or reduces their ability to experience normal pleasures, are key areas of concern regarding animal agriculture and biomedical research. However, probing the emotional lives of animals is one of the most difficult challenges facing science. Our aim for this paper is not to provide a comprehensive review of the growing literature in animal pain (see Rutherford, 2002), but to work through some of the key conceptual and methodological issues important to the assessment and prevention of this pain.

Attitudes regarding pain in humans have shifted considerably in recent history. For example, Pernick (1985) documents that in Pennsylvania in the 1860 s some $30 \%$ of amputations on human patients were performed without anaesthesia, despite the fact that drugs were readily available and inexpensive. Instead, anaesthesia was reserved for those patients thought to be most sensitive to pain: whites, women and the wealthy. Those thought to be insensitive to pain included recent immigrants, blacks, poor, the uneducated and alcoholics. Attitudes towards treatment of pain in children are still in flux (see Anand and Craig, 1996), with some arguing that infants less than a year of age likely do not experience pain (Derbyshire, 2003). These attitudes have likely held up progress on addressing painful procedures in neonates. For example, it is only recently that researchers have begun to investigate methods of treating pain associated with circumcision in male infants (e.g. Kurtis et al., 1999).

Attitudes regarding pain in animals are also evolving. For example, even in the late 1980s the majority of animal researchers interviewed in New York City reported that no analgesics were given to laboratory 
animals recovering from surgery, and that no plans were in place to begin providing analgesics (Phillips, 1993). A recent study surveyed the use of analgesics for laboratory rodents following surgery as reported in peer-reviewed journal articles published in the 1990s and early 2000s, and the results suggest that while analgesic provision increased over this period, a large proportion of animals in both periods were not receiving sufficient analgesia (Richardson and Flecknell, 2005).

Even when people acknowledge the potential for animals to experience pain, appropriate treatment does not always follow. For example, a recent study examining the attitudes of French veterinarians found that $96 \%$ of respondents were "moderately or extremely concerned about recognition and alleviation of animal pain" (Hugonnard et al., 2004). However, for cats and dogs, analgesic use by respondents ranged from a high of $84 \%$ following orthopaedic surgery to a low of only $17 \%$ following castration. The top two reasons provided for a lack of treatment were "difficulties in recognizing pain" and "lack of knowledge about appropriate therapy", highlighting the need for further research and training in this area.

\section{Pain assessment}

Research to date on pain assessment in animals has tended to use one of three approaches: measures of general body functioning such as food and water intake or weight gain, measures of physiological responses such as plasma cortisol concentrations, and measures of behaviour such as vocalizations. All three approaches have merit and can be useful in different contexts. Basic productivity measures, such as changes in food intake, are often the easiest to measure, at least for singly housed animals. However, these measures do not reflect what is happening to the animal now, but rather what was happening over the interval between observations (typically hours for food and water consumption and days for changes in body weight).

There is a long history of using physiological responses in assessing pain and distress (for review see Gregory, 2004). Measures include responses of the sympathetic-adrenomedullary system, such as changes in heart rate due to release of norepinephrine, and responses of hypothalamic-pituitaryadrenocortical system, such as concentrations of cortisol, adrenocorticotropic hormone and corticotropinreleasing factor. In principle at least, these measures may be particularly useful in prey species such as cattle that are considered stoic and unlikely to show pronounced behavioural responses to pain until injuries are advanced. Also, in some situations we may wish to assess pain in animals that are physically restrained, such as deer restrained in a crush during velvet antler removal (e.g. Woodbury et al., 2002). Although these physiological measures can be useful in experimental and laboratory settings, the technical requirements make them less useful for on-farm assessments. Furthermore, the measurements can themselves require animal restraint and tissue sampling, which can be stressful and may confound the results.

In this paper we focus on behavioural examples, although many of the issues apply equally to the other types of measure. For any measure we must begin with a critical look at whether the measure is likely to provide us with useful information about the pain that the animal is experiencing. Logically, we cannot use a measure to assess pain associated with a procedure unless the measure is validated, but what kind of evidence is necessary to determine the validity of pain response measures?

\subsection{Validating response measures}

The gold standard for validating response measures comes from studies that examine responses with $(P)$ and without $(p)$ a condition causing pain, and with $(A)$ and without $(a)$ analgesics known to be effective at treating this pain. The most useful measures will distinguish $P a$ but show no difference among the other three conditions (i.e. PA, $p A$ and $p a$ ). The $P a$ versus pa comparison allows us to determine (1) if there is 
a change in behaviour associated with a condition that can be assumed to cause pain and (2) if this behavioural change is due simply to environmental or other non-pain factors associated with the condition. For example, lame cows show shortened strides and slower walking speeds (Flower et al., 2005), but so do cows walking on wet, slippery surfaces found in many barns (Phillips and Morris, 2000); if animals were tested on slippery surfaces, changes in gait might be due to the testing environment rather than a painful condition. To identify gait characteristics associated with painful injuries, animals with and without injuries ( $P$ versus $p$ ) must be observed under conditions that do not confound the behaviour of interest.

Physical injuries and diseases can also cause a loss in normal functioning, regardless of whether pain is present. For example, joint injuries may prevent normal movement of the joint, leading to stiffness in gait that may not be associated with pain. The use of an analgesic treatment (i.e. PA versus $P a$ ) allows us to distinguish the effect of pain from other effects of the condition. However, use of an analgesic treatment also comes with a risk: these treatments can have general inhibitory or excitatory effects on behaviour, such as the well-known sedative effects of opiates. Thus it is also important to examine the responses of uninjured animals with and without analgesics (i.e. $p A$ versus $p a$ ) to determine if the analgesic causes a difference in the behaviour even in the absence of pain.

An example from our research group is work on behaviours indicative of pain after dehorning (removal of the horn buds) in dairy calves (Faulkner and Weary, 2000). We were interested in documenting the behaviours shown by 4-8-week-old calves in the hours following the common dairy industry procedure of dehorning using a hot-iron. This procedure is believed to cause severe pain, and is associated with behavioural and physiological responses (e.g.; Morisse et al., 1995; Petrie et al., 1996; McMeekan et al., 1998a). Giving calves a local anaesthetic before dehorning reduces behaviours like tail wagging, head movements, tripping and rearing that typically occur during this procedure. A local anaesthetic also reduces behaviours like head rubbing, head shaking and ear flicking that occur in the first few hours after the procedure (Morisse et al., 1995; Sylvester et al., 1998; Graf and Senn, 1999; McMeekan et al., 1999). Unfortunately, local anaesthetics like lidocaine are only effective for about $3 \mathrm{~h}$ after they are administered (e.g. McMeekan et al., 1998a,b). Non-steroidal anti-inflammatory drugs (NSAIDs) are known to be effective at reducing post-operative pain in the hours that follow the procedure, but are these same behavioural measures valid indicators of pain over this period?

In our experiment we gave all calves a local block with lidocaine, and provided a pre-operative sedative to reduce the response to the injection of the local anaesthetic and eliminate the need for physical restraint during the procedure (see Grøndahl-Nielsen et al., 1999). Calves were then either dehorned or a put through a sham procedure ( $P$ versus $p$ ), with or without the NSAID ketoprofen ( $A$ versus $a$ ). The number of ear flicks shown by calves during the $24 \mathrm{~h}$ after the procedure is illustrated in Fig. 1 . Calves that experienced the sham procedure with or without the NSAID showed almost no ear flicks, as did calves that were dehorned and received the NSAID. However, calves that were dehorned without the NSAID showed high frequencies of this behaviour throughout the $24 \mathrm{~h}$ after the procedure, demonstrating that this response is indicative of post-procedural pain.

An additional twist to validation studies is to demonstrate that the change in the response declines in a dose dependent manner with the quantity of analgesic provided. In a recent example, Roughan and Flecknell (2003) took qualitative and quantitative measures of behaviour from rats following abdominal surgery. Rats were provided with either saline (control) or the analgesic meloxicam at $0.5,1 \mathrm{or} 2 \mathrm{mg} / \mathrm{kg} 1$ $\mathrm{h}$ before surgery. This study showed a dose dependent decrease in both a subjective pain score and in the frequency of behaviours such as back arching, writhing and staggering. The study also showed a dose dependent increase in the frequency of behaviours such as normal gait and rearing. The advantages of the dose-response model include the ability to draw stronger inferences regarding the 
effect of treatment, and to describe the shape of the response function between the treatment and the pain measure.

Fig. 1. Behavioural response of calves during the $24 \mathrm{~h}$ after either dehorning or a sham procedure. For both conditions calves were tested with and without a non-steroidal anti-inflammatory drug (NSAID). Adapted from Faulkner and Weary (2000).

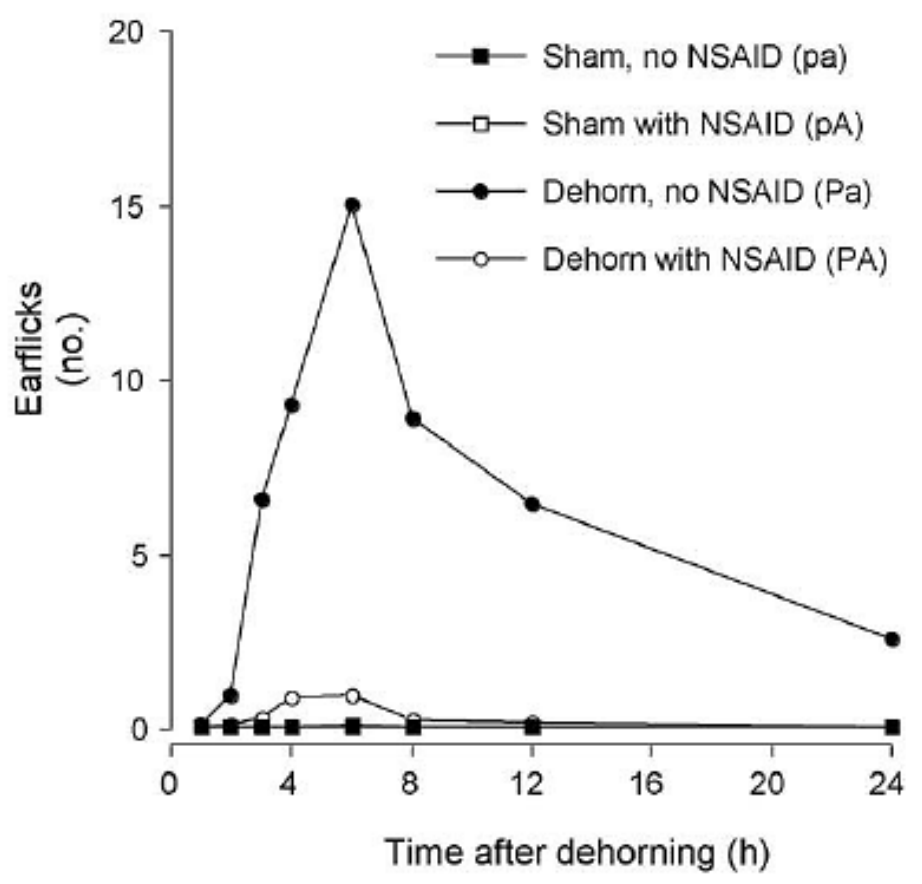

Responses to pain can be used in two manners. Firstly, they can be used to assess whether a given procedure generally causes pain and to test the efficacy of an analgesic regime that will be used in a blanket manner for all animals. Secondly, they can be used to assess whether an individual animal is in pain or has received sufficient analgesia. Although some variability in response is acceptable when assessing a procedure in a group of animals, greater specificity is necessary to use a measure for monitoring individual animals.

\subsection{Objective versus subjective methods}

As illustrated by the Roughan and Flecknell (2003) example, both subjective and objective measures of behaviour can be used in pain assessment. Subjective scoring systems have been particularly popular in the veterinary literature, perhaps because these are considered relatively easy to apply in a clinical setting. A well-known example is gait scoring systems to assess lameness in cattle, such as the 5-point scale developed by Sprecher et al. (1997). These systems normally rely on the presence or absence of several key behaviours, such as an arched back, shortened strides, and limb favouring. Unfortunately, the behaviours that are included in each system vary from author to author, with little apparent justification. One recent study attempted to systematically assess the value of specific behaviours, but found that no one behaviour or combination of behaviours was better than the overall gait score in identifying cows with sole ulcers (Flower and Weary, 2006). Unfortunately, little work to date has attempted to validate such gait measures specifically in relation to pain, and none to our knowledge has used the appropriate controls and analgesic treatments described above. 
The issue of validity relates to both subjective and objective measures, but subjective measures are more prone to poor reliability. The reliability of a measure refers to its potential for obtaining the same results when scoring is repeated. This can be evaluated by having the same observer re-score animals on multiple occasions (intra-observer reliability), or by having different observers independently score the animals (inter-observer reliability). For example, Winckler and Willen (2001) compared scores of three observers for 147 dairy cows, and found that the lameness scores were in agreement for $63-74 \%$ of observations. In another study, O'Callaghan et al. (2003) found that the scores of two observers agreed only $37 \%$ of the time, and a single observer was consistent in re-scoring cows for only $56 \%$ of observations. Such low levels of inter- and intra-observer reliability obviously limit the usefulness of a measure, and place an upper limit on the extent to which the measure can be validated.

Partly because of the limitations of these subjective measures, our research group and others have been exploring quantitative measures of posture and gait for detecting painful injuries. Flower et al. (2005) took quantitative measures of cow gait using methods developed to study human kinematics. This study showed that several objective measures of cow gait, such as stride length and duration, differed when animals had painful sole ulcers. In comparison to healthy animals, cows with injuries took longer to take each step, and spent almost twice as much time with their weight supported by three legs during walking as opposed to just two.

Although such quantitative gait measures can be recorded with a high degree of consistency (in the case of Flower et al., 2005, temporal measures were accurate to within $0.03 \mathrm{~s}$ and spatial measures to within a few $\mathrm{cm}$ ), they will not necessarily provide a better measure of pain than do the subjective scoring systems described above. For this and other applications the relative value of the two approaches will depend upon the type of pain experienced, the quality of the measures, and in the case of the subjective methods, the training of the observer. Ultimately, pain researchers will need to develop measures that are both sensitive and specific, and work with clinicians and other professionals to make measures reasonably efficient and practical for real-time assessments in farms, laboratories and other animal facilities.

\subsection{Types of behavioural assessment}

Three main classes of behaviours can be useful in pain assessment. The most obvious of these are painspecific behaviours, like the writhing shown by rats after abdominal surgery (Roughan and Flecknell, 2003), or the increased number of high-frequency calls produced by piglets during castration (Taylor and Weary, 2000). Defensive behaviours can sometimes also be seen when the animal or site of injury is manipulated, such as bucking in lambs upon palpation of the scrotum following castration (Thornton and Waterman-Pearson, 1999). A painful injury will sometimes increase the animal's sensitivity to other sources of pain, and such hyperalgesia is typically assessed by exposing the animals to a painful stimulus (e.g. heat or pressure) and measuring the withdrawal response (e.g. Whay et al., 1998). The site and intensity of pain and its duration will influence the severity of these responses, and the sorts of behaviours that are observed. For example, calves respond to application of the hot-iron by performing vigorous escape behaviours such as tripping forward onto the front legs and rearing, but respond to the post-operative pain with more subtle injury-directed behaviours such as ear flicking and head shaking (e.g. Grøndahl-Nielsen et al., 1999).

A second class of pain response is the decline in the frequency or magnitude of certain behaviours. General lethargy has long been regarded as a sign of pain in animals (Morton and Griffiths, 1985), and pain studies often include measures of both reduced activity, such as normal gait (e.g. Roughan and Flecknell, 2003), or reactivity, such as latency to withdraw from a handler (Thornton and WatermanPearson, 1999). Particularly informative are those behaviours that animals would otherwise be highly 
motivated to perform. For example, rats and mice kept in conventional laboratory housing are often fed from a 'hopper' above the cage that they access by rearing on their hind legs. These rearing and stretching movements might well be painful after abdominal surgery, providing a reasonable basis for the prediction that these movements will decline. The decline in these behaviours also comes at a clear cost to the animal - in this case reduced food intake.

A third class of pain measure are those of choice or preference. Measures of choice were among the first behaviours to be used in field of animal welfare science (e.g. Hughes and Black, 1973), and can be used to evaluate how animals perceive the relative value or aversiveness of different treatments. Through repeated exposures to the alternatives, animals can learn what to expect, and avoidance learning has been used to evaluate animals' responses to potentially painful treatments. For example, Rushen (1986) used this approach to evaluate how sheep respond to electro-immobilization, a procedure used to temporarily restrain animals during shearing. In this study, Rushen moved sheep along a runway to an area where they were sheared with and without electro-immobilization. Over repeated trials, sheep that had learned to expect electro-immobilization became more difficult to move along the runway than those that received the other treatments, indicating that this procedure is aversive.

Further refinements to this general approach include titrating one treatment against another. In a recent example, Webster and Fletcher (2004) evaluated the responses of hens to environments with high concentrations of carbon dioxide gas. These authors used an approach-avoidance test, by first training the birds to expect food in the test cage after a period of food deprivation. Hens proved willing to enter the cage to eat even at gas concentrations that other animals normally avoid, suggesting that birds do not find these concentrations aversive.

In what is arguably the most convincing form of choice study from the perspective of pain assessment, animals can be trained to self-medicate with analgesics, and researchers can directly assess the frequency and amounts administered. For example, Danbury et al. (2000) trained lame and sound broilers to discriminate between two feeds, one containing an analgesic, and found that lame birds consumed more of the food containing analgesic.

\section{Pain prevention and mitigation}

Recognizing pain only takes us part way - we also need to find ways of reducing or preventing its occurrence. One obvious approach to avoiding pain is to dispense with the procedures that cause it, but the practicality of this option will depend upon the purpose of the procedure and the availability of feasible alternatives. We can also prevent injury and disease that cause pain, or minimize the effects by finding better methods for early diagnosis and treatment.

\subsection{Prevention and early treatment of injury and disease}

Many cases of painful injury and disease can be avoided by refinements in animal care. For example, mastitis is a common and painful infection of the udder in lactating cows that can be largely prevented through proper management practices. Some types of mastitis result from contamination of the udder by bacteria in the bedding and we can reduce the incidence of mastitis by ensuring that bedding is dry and free of fecal contamination, and by using inorganic bedding like sand that caries lower bacterial loads than organic substrates like sawdust (Zdanowicz et al., 2004). In some instances, high levels of productivity can increase the risk of painful disease. For example, selection for increased growth rates has resulted in an increased incidence of skeletal deformities leading to severe lameness in the legs of broiler chickens (see Thorp, 1994). 


\subsection{Is the procedure needed?}

Painful procedures performed on animals are normally assumed to provide some concrete benefit to either the animal or its caretaker, but research can sometimes allow us to reconsider whether the procedure is really needed, at least in its current form. For example, in recent years dairy farmers have begun tail docking their animals in an attempt to reduce the risk of mastitis on their farms. This is a laudable aim, and an approach that would appear to make sense - in typical indoor housing systems the tail often becomes contaminated with faeces and urine and this excreta-soaked fly swatter would seem to spread pathogens across the cow's body including her udder and teat ends. However, a series of experiments - involving thousands of animals with docked and intact tails - have failed to show such benefits, and most importantly found no effect on udder health and mastitis (Eicher et al., 2001; Tucker et al., 2001; Schreiner and Ruegg, 2002). These findings are already leading to fewer dairy producers using this procedure on their farms.

In other cases a painful but necessary procedure can be eliminated through the use of selective breeding for desired traits. For example, calf dehorning is normally considered necessary to prevent injury to other cattle and to animal handlers, but the development of polled lines (i.e. animals that are genetically hornless) through selective breeding has negated the need for this procedure in some breeds of beef cattle.

\subsection{How can we reduce pain?}

Some painful procedures do provide clear benefits. In the first few days after birth, piglets compete with their littermates to secure access to preferred teats on the sow's udder. To help them in this competition, piglets are born with 'needle' teeth that protrude sideways and lacerate the faces of their competitors. To prevent these injuries pig producers typically remove the needle teeth by clipping them to the gum line, but this procedure exposes the pulp cavity, increasing the risks of tooth infection, damage to the gums, and injuries to the mucous membrane of lips caused by splintered teeth. However, a simple refinement to this procedure - grinding or clipping only the distal tip of the tooth - can much reduce the risk of these complications (Hutter et al., 1994).

Unfortunately, attempts at such refinements do not always lead to a reduction in the amount of pain that animals experience. For example, during piglet castration there is variation in the way piglets are held, in the methods used to cut the scrotum, and in the way the spermatic cords are severed, but studies by our research group have failed to identify alternatives that cause less pain. In one study we tested the longstanding assumption that performing such procedures at younger ages will result in less pain (Taylor et al., 2001), by monitoring vocal responses that had been validated in earlier studies. When compared to responses to a sham procedure, castrated piglets showed a similar increase in vocalizations (especially calls greater than $1 \mathrm{kHz}$ in frequency) regardless of whether the procedure was performed at 3, 10 or 17 days of age. Work on human babies is also challenging the idea that neonates have limited ability to feel pain and actually suggests that painful experiences early in life can accentuate sensitivity to pain at older ages (Pattinson and Fitzgerald, 2004).

One of the most obvious refinements for injury and disease and for painful procedures is the provision of anaesthetics and analgesics. Although there are many excellent examples where such treatments are effective and appropriate (see Benson, 2004), it is also important to consider that any restraint required to administer the drugs may be distressing for the animal, and methods of administration (such as repeated injections necessary for a ring block) can themselves be painful. It is perhaps equally important to consider the practicality of measures used to mitigate pain. In the calf-dehorning example presented above (Faulkner and Weary, 2000), the pain of hot iron dehorning could be controlled using a sedative, a 
local block consisting of a series of injections, and NSAIDs to control post-operative pain. However, it is difficult to convince dairy producers to adopt such an elaborate approach. One way of increasing adoption is to find methods that are inexpensive and easy to apply, or provide benefits to the producers, or ideally both. For example, Vickers et al. (2005) recently showed that the pain and distress due to caustic paste dehorning can be controlled using only one injection of the drug xylazine (an inexpensive sedative and mild analgesic). Producers also benefit because the sedative makes the chore easier and requires less labour to perform.

\subsection{Constraints on adopting refinements}

Although better scientific and technical solutions play an important role in encouraging animal users to adopt procedures that prevent and mitigate pain, it is also important to recognize some of the cultural and economic constraints on adoption. For example, some effective drugs are not certified for use in all countries, and in other cases can only be dispensed by a veterinarian. The drug xylazine, mentioned above, can only be used under the supervision of a licensed veterinarian in Canada. In some cases this may not be a problem - large dairy producers well serviced by local practitioners can include this treatment as part of regular herd health visits. However, for isolated ranchers living sometimes hundreds of kilometres from the nearest veterinarian, this becomes an important constraint. Sometimes solutions to such problems can be found through cooperation among the affected parties, such as an agreement by the Alberta Veterinary Medical Association to train and certify elk ranchers in the use analgesics when amputating antlers used to produce medicinal velvet.

In some U.S. states, cattle grazing on publicly owned land must be branded as a form of legal identification, and re-branding can be required when animals move or change ownership. New regulations proposed by the USDA (2005) would require that feeder cattle entering the U.S. from Canada be branded with a ' $\mathrm{C}$ ' and ' $\mathrm{N}$ ', despite the fact that most of beef cattle already have a distinctive brand and that all Canadian cattle must by law have ear tags that can be used to track the animals to the farm of their origin. In this example, there may also be cultural factors at play that underemphasize the importance of pain, with some western beef producers arguing that procedures like hot-iron branding have "no effect on cattle" (Thomas, 2000). In such cases, economic factors can act as incentives for producers and regulators to consider change. For example, the Burger King Corporation has indicated that it will not buy beef from animals that have been repeatedly branded for animal identification, and similar economic constraints could be used to speed the adoption of alternatives such as use of polled breeds in lieu of dehorning.

\section{Philosophical issues}

The study of pain is of special interest in that it provides a particularly well-developed template for the study of animal feelings. Pain in humans and other animals can be defined as the unpleasant sensory and emotional experience associated with actual or potential tissue damage, or described in terms of such damage (IASP, 1979). This begs the question of how can we really know the emotions experienced by another being? Logically, emotional states are private and we can only be certain of our own experiences. Inquiry into the affective condition of others is normally based on J.S. Mills' argument by analogy (see Dawkins, 1980). Briefly, the feelings of another being (even another human) are ultimately private - we cannot be certain that they experience the world like ourselves. We can see that we share similarities in ancestry, anatomy, etc., and that we respond in a similar way to similar situations. This does not allow us to conclude they experience the identical feelings that we do, but we can use the strength of the similarities to justify inferences about that individual's subjective state. What makes pain so suitable for study is that much basic research is already available to address key aspects of this argument. Specifically, the structures and pathways used to send and receive pain signals are well known in 
humans and animals, and much is known about pharmacological methods of pain mitigation. When backed up with reasonable evidence for the analogy, denying the existence of similar states would seem absurd (see Bateson, 1991).

Some scientists have, surprisingly, suggested that animals are incapable of experiencing pain. A prominent example is psychologist Bermond $(1997,2001)$ who distinguishes between "the registration of pain as a stimulus, which does not induce feelings of suffering, and the experience of pain as an emotion, which does induce suffering" (2001, p. S47). Bermond argued that responding to pain as a stimulus, which can occur at the level of the spinal cord, "developed much earlier in evolution than the experience of pain suffering" (S53). He noted that for humans the unpleasant emotional experience of pain requires the involvement of the prefrontal cerebral cortex. For example, damage to this area of the cortex tends to leave the human patient able to perceive pain as a stimulus but indifferent to it. Given that only humans and the anthropoid apes show a well-developed prefrontal cortex, Bermond concluded that although many species may register and respond to pain as a stimulus, only humans and the anthropoid apes have the capacity to suffer as a result. Other species would be like humans with prefrontal cortex damage: able to respond to pain stimuli, but immune from any associated emotional experience.

One rejoinder to these arguments is that similar functions are often served by different neural structures in different species. As noted by Braithwaite and Huntingford (2004), "comparisons of avian and mammalian visual systems clearly illustrate how different taxonomic groups can perceive and process the same type of information but through different pathways and neural structures". Hence, it seems entirely possible that species lacking a well-developed prefrontal cortex may still experience harmful stimuli as unpleasant via other brain structures. If that is the case, then the actual affective experience may be quite different from one species to another.

Although the skepticism of Bermond and others does not appear to be widely shared by scientists, it forces us to think carefully about what kind of observations could serve as definitive evidence for or against the experience of pain and other affective states in animals. The simple fact that animals have the type of nociceptors and nerve fibres that are used to transmit pain in humans does not by itself show that the animals experience unpleasant feelings of pain because the unpleasantness may depend on how the information is processed in the brain. The occurrence of physiological changes, such as increased heart rate or secretion of catecholamines, does not prove that the animal experiences a stimulus as unpleasant because similar physiological adjustments can be made unconsciously or even in response to pleasant stimuli. Even behavioural reactions are not definitive; we know, for example, that humans can suddenly withdraw a hand from fire as a reflexive action organized at the level of the spinal cord in the absence of conscious experience of pain. Even responses such as limping could conceivably occur as unconscious adjustments to injury.

A possible solution was proposed by neurophysiologist Gentle (2001) in a study of pain in chickens. He noted that the human experience of pain can be mitigated by redirecting the patient's attention elsewhere through such methods as relaxation training, hypnosis and other therapies. He reasoned that if a chicken's reaction to a harmful event was simply an unconscious, automatic reaction, then shifting the bird's attention should not influence the response. If, however, the chicken felt the pain in the sense of an unpleasant experience, then redirecting the bird's attention might reduce the signs of pain, as it does in the case of humans. Gentle studied chickens that received an injection of sodium urate crystals into one leg joint, producing changes in behaviour consistent with mild pain lasting about $3 \mathrm{~h}$. Birds that were kept in their barren home cage during this time would avoid putting weight on the affected leg; instead they would spend their time sitting or standing on the good leg, and if encouraged to walk they would do so with a limp. However, these changes in behaviour were greatly reduced or eliminated by placing the bird into a pen with a novel feature (wood shavings on the floor) and especially if a second, unfamiliar chicken 
was present to further distract the injected bird's attention. The same response occurred if the injection was given shortly before the hen was due to lay an egg - a time when hens are strongly focused on finding a suitable nesting place - but pain-related behaviour resumed after the egg had been laid. Gentle concluded that because the birds' reaction to the injection was modified by shifting its attention elsewhere, the reaction cannot have been an unconscious adjustment of behaviour that happened automatically. Instead, it must have been mediated by conscious awareness of the pain.

Arguments such as those of Bermond actually play only a limited role in scientific thought. As noted by Kuhn (1996) in The Structure of Scientific Revolutions, scientific thinking does not generally change because an existing theory is perceived or claimed to be faulty. Rather, scientific thinking changes when a new idea provides a more satisfactory explanation for what is observed. Thus for Bermond's arguments to be accepted, Bermond would need not merely to present arguments against the view that animals consciously experience pain, but produce alternative explanations that account for the available data in more satisfactory ways, for example by explaining why Gentle's chickens stopped limping when they were distracted if they had no conscious awareness of the pain. Until this happens, the attribution of states such as pain, fear and hunger to other species seems likely to continue playing an important role in our understanding of their behaviour and their welfare.

\section{Summary}

The study of pain in animals is important and interesting because of the ethical implications and conceptual and scientific challenges that it raises. If we acknowledge that animals have the capacity to experience pain, then we are obligated to minimize its occurrence, through both prevention and treatment. The first step is to develop valid and reliable techniques for the assessment of pain in practical settings. The second step is to use these techniques to identify ways to reduce injury and disease and to refine procedures that are painful but necessary. Finally, the implementation of these refinements will require cooperation by all stakeholders to address regulatory, technological and economic constraints.

\section{Acknowledgments}

We are grateful to our colleagues in the Animal Welfare Program for discussions about pain assessment and mitigation in animals. Our work is supported by the Natural Sciences and Engineering Research Council of Canada through the Industrial Research Chair in Animal Welfare, and by contributions from the British Columbia SPCA, the BCVMA, the BC Dairy Foundation and many other donors listed on our web site at http://www.landfood.ubc.ca/animalwelfare/.

\section{References}

Anand, K.J.S., Craig, K.D., 1996. New perspectives on the definition of pain. Pain 67, 3-6.

Bateson, P., 1991. Assessment of pain in animals. Anim. Behav. 42, 827-839.

Benson, G.J., 2004. Pain in farm animals: nature, recognition, and management. In: Benson, G.J., Rollins, B.E. (Eds.), The Well-being of Farm Animals: Challenges and Solutions. Blackwell, Oxford, pp. 61-84.

Bermond, B., 1997. The myth of animal suffering. In: Dol, M., Kasanmoentalib, S., Lijmbach, S., Rivas, E., van den Bos, R. (Eds.), Animal Consciousness and Animal Ethics. Van Gorcum, Assen, The Netherlands, pp. 125-143. 
Bermond, B., 2001. A neuropsychological and evolutionary approach to animal consciousness and animal suffering. Anim. Welfare 10, S47-S62.

Braithwaite, V.A., Huntingford, F.A., 2004. Fish and welfare: Do fish have the capacity for pain perception and suffering? Anim. Welfare 13, S87-S92.

Danbury, T.C.,Weeks, C.A., Chambers, J.P.,Waterman-Pearson, A.E., Kestin, S.C., 2000. Self-selection of the analgesic drug carprofen by lame broiler chickens. Vet. Rec. 146, 307-311.

Dawkins, M.S., 1980. Animal Suffering: The Science of Animal Welfare. Chapman and Hall, London.

Derbyshire, S.W.G., 2003. Fetal "pain" - a look at the evidence. Am. Pain Soc. Bull. 13, 1-4.

Eicher, S.D., Morrow-Tesch, J.L., Albright, J.L., Williams, R.E., 2001. Tail-docking alters fly numbers, flyavoidance behaviors, and cleanliness, but not physiological measures. J. Dairy Sci. 84, 1822-1828.

Faulkner, P., Weary, D.M., 2000. Reducing pain after dehorning in dairy calves. J. Dairy Sci. 83, 20372041.

Flower, F.C., Sanderson, D.J., Weary, D.M., 2005. Hoof pathologies influence kinematic measures of dairy cow gait. J. Dairy Sci. 88, 3166-3173.

Flower, F.C.,Weary, D.M., 2006. Effect of hoof pathologies on subjective assessments of dairy cow gait. J. Dairy Sci. 89, 139-146.

Gentle, M.J., 2001. Attentional shifts alter pain perception in the chicken. Anim. Welfare 10, S187-S194.

Graf, B., Senn, M., 1999. Behavioural and physiological responses of calves to dehorning by heat cauterisation with or without local anaesthesia. Appl. Anim. Behav. Sci. 62, 153-171.

Gregory, N., 2004. Physiology and Behaviour of Animal Suffering. Blackwell, Oxford.

Grøndahl-Nielsen, C., Simonsen, H.B., Damkjer Lund, J., Hesselholt, M., 1999. Behavioral, endocrine and cardiac responses in young calves undergoing dehorning with or without the use of sedation and analgesia. Vet. J. 158, 14-20.

Hughes, B.O., Black, A.J., 1973. The preference of domestic hens for different types of battery cage floor. Brit. Poultry Sci. 14, 615-619.

Hugonnard, M., Leblond, A., Keroack, S., Cadore, J., Troney, E., 2004. Attitudes and concerns of French veterinarians towards pain and analgesia in dogs and cats. Vet. Anaesth. Analg. 31, 154-163.

Hutter, S., Heinritzi, K., Reich, E., Ehret, W., 1994. Efficacité de différentes méthodes de résection des dents chez le porcelet non sevré. Revue Med. Vet. 145, 205-213.

International Association for the Study of Pain, 1979. Pain terms: a list with definitions and notes on usage. Pain 6, 249-252.

Kuhn, T., 1996. The Structure of Scientific Revolutions, 3rd ed. University of Chicago Press, Chicago.

Kurtis, P.S., DeSilva, H.N., Bernstein, B.A., Malakh, L., Schechter, N.L., 1999. A comparison of the Mogen and Gomgo clamps in combination with dorsal penile nerve block in minimizing the pain of neonatal circumcision. Pediatrics 103, e23. 
McMeekan, C.M., Stafford, K.J., Mellor, D.J., Bruce, R.A., Ward, R.N., Gregory, N.G., 1998a. Effects of regional analgesia and/or non-steroidal anti-inflammatory analgesic on the acute cortisol response to dehorning calves. Res. Vet. Sci. 64, 147-150.

McMeekan, C.M., Mellor, D.J., Stafford, K.J., Bruce, R.A., Ward, R.N., Gregory, N.G., 1998b. Effects of local anaesthesia of 4 to 8 hours' duration on the acute cortisol response to scoop dehorning in calves. Aust. Vet. J. 76, 281-285.

McMeekan, C.M., Stafford, K.J., Mellor, D.J., Bruce, R.A., Ward, R.N., Gregory, N.G., 1999. Effects of a local anaesthetic and a non-steroidal anti-inflammatory analgesic on the behavioural responses of calves to dehorning. N. Z. Vet. J. 47, 92-96.

Morisse, J.P., Cotte, J.P., Huonnic, D., 1995. Effect of dehorning on behaviour and plasma cortisol responses in young calves. Appl. Anim. Behav. Sci. 43, 239-247.

Morton, D.B., Griffiths, P.H.M., 1985. Guidelines on the recognition of pain, distress and discomfort in experimental animals and hypothesis for assessment. Vet. Rec. 116, 431-436.

O'Callaghan, K.A.O., Cripps, P.J., Downham, D.Y., Murray, R.D., 2003. Subjective and objective assessment of pain and discomfort due to lameness in dairy cattle. Anim. Welfare 12, 605-610.

Pattinson, D., Fitzgerald, M., 2004. The neurobiology of infant pain: development of excitatory and inhibitory neurotransmission in the spinal dorsal horn. Region. Anesth. Pain Med. 29, 36-44.

Pernick, M.S., 1985. A Calculus of Suffering: Pain, Professionalism and Anesthesia in Nineteenth Century America. Columbia University Press, New York.

Petrie, N.J., Mellor, D.J., Stafford, K.J., Bruce, R.A., Ward, R.N., 1996. Cortisol responses of calves to two methods of disbudding used with and without local anaesthetic. N. Z. Vet. J. 44, 9-14.

Phillips, M.T., 1993. Savages, drunks, and lab animals: the researcher's perception of pain. Soc. Anim. 1, 61-81.

Phillips, C.J., Morris, I.D., 2000. The locomotion of dairy cows on concrete floors that are dry, wet, or covered with a slurry of excreta. J. Dairy Sci. 83, 1767-1772.

Richardson, C.A., Flecknell, P.A., 2005. Anaesthesia and post-operative analgesia following experimental surgery in laboratory rodents: Are we making progress? ATLA 33, 1-9.

Roughan, J.V., Flecknell, P.A., 2003. Evaluation of a short duration behaviour-based post-operative pain scoring system in rats. Eur. J. Pain 7, 397-406.

Rushen, J., 1986. Aversion of sheep to electro-immobilization and physical restraint. Appl. Anim. Behav. Sci. 15, 315-324.

Rutherford, K.M.D., 2002. Assessing pain in animals. Anim. Welfare 11, 31-53.

Schreiner, D.A., Ruegg, P.L., 2002. Tail docking and milk quality. J. Dairy Sci. 85, 2513-2521.

Sprecher, D.J., Hostetler, D.E., Kaneene, J.B., 1997. A lameness scoring system that uses posture and gait to predict dairy cattle reproductive performance. Theriogenology 47, 1179-1187. 
Sylvester, S.P., Mellor, D.J., Stafford, K.J., Bruce, R.A., Ward, R.N., 1998. Acute cortisol responses of calves to scoop dehorning using local anaesthesia and/or cautery of the wound. Aust. Vet. J. 76, 118122.

Taylor, A.A., Weary, D.M., 2000. Vocal response of piglets to castration: identifying procedural sources of pain. Appl. Anim. Behav. Sci. 70, 17-26.

Taylor, A.A.,Weary, D.M., Lessard, M., Braithwaite, L.A., 2001. Behavioral response of piglets to castration: the effect of piglet age. Appl. Anim. Behav. Sci. 73, 35-43.

Thomas, L., 2000. Is it time to go polled? Can. Cattlemen 22-23.

Thornton, P.D., Waterman-Pearson, A.E., 1999. Quantification of the pain and distress responses to castration in young lambs. Res. Vet. Sci. 66, 107-118.

Thorp, B.H., 1994. Skeletal disorders in the fowl - a review. Avian Pathol. 23, 203-236.

Tucker, C.B., Fraser, D., Weary, D.M., 2001. Tail docking dairy cattle: effects on cow cleanliness and udder health. J. Dairy Sci. 84, 84-87.

USDA, 2005. Bovine spongiform encephalopathy: minimal risk regions and importations of commodities; final rule and notice. Federal Register 70, 459-538.

Vickers, K.J., Niel, L., Kiehlbauch, L.M.,Weary, D.M., 2005. Calf response to caustic paste and hot-iron dehorning using sedation with and without local anesthetic. J. Dairy Sci. 88, 1454-1459.

Webster, A.B., Fletcher, D.L., 2004. Assessment of the aversion of hens to different gas atmospheres using an approach-avoidance test. Appl. Anim. Behav. Sci. 88, 275-287.

Whay, H.R., Waterman, A.E., Webster, A.J.F., O'Brien, J.K., 1998. The influence of lesion type on the duration of hyperalgesia associated with hind-limb lameness in dairy cattle. Vet. J. 156, 23-29.

Winckler, C., Willen, S., 2001. The reliability and repeatability of a lameness scoring system for use as an indicator of welfare in dairy cattle. Acta Agric. Scand., Sect. A, Suppl. 30, 103-107.

Woodbury, M.R., Caulkett, N.A., Wilson, P.R., 2002. Comparison of lignocaine and compression for velvet antler analgesia in wapiti. Can. Vet. J. 43, 869-872.

Zdanowicz, M., Shelford, J.A., Tucker, C.B.,Weary, D.M., von Keyserlingk, M.A.G., 2004. Bacterial populations on teat ends of dairy cows housed in free stalls and bedded with either sand or sawdust. $\mathrm{J}$. Dairy Sci. 87, 1694-1701. 